\title{
1 Relating industrial symbiosis and circular economy to the sustainable development debate ${ }^{1}$
}

\author{
Andrea Cecchin $^{1,2}$, Roberta Salomone ${ }^{3}$, Pauline Deutz ${ }^{4}$, Andrea Raggi ${ }^{5}$, \\ Laura Cutaia 6 \\ ${ }^{1}$ North Dakota State University, Department of Plant Sciences, USA, e-mail: \\ andrea.cecchin@ndsu.edu \\ ${ }^{2}$ University of North Dakota, Department of Earth System Science \& Policy, \\ USA \\ ${ }^{3}$ University of Messina, Department of Economics, Italy, e-mail: \\ roberta.salomone@unime.it \\ ${ }^{4}$ University of Hull, Department of Geography, Geology and Environment, \\ UK, e-mail: p.deutz@hull.ac.uk \\ ${ }^{5}$ University "G. d'Annunzio" of Chieti-Pescara, Department of Economic \\ Studies, Italy, e-mail: a.raggi@unich.it \\ ${ }^{6}$ ENEA, SSPT-USER-RISE, Italy, e-mail: laura.cutaia@enea.it
}

\begin{abstract}
Industrial Symbiosis (IS) is a business-focused collaborative approach oriented towards resource efficiency that has been theorised and studied mainly over the last twenty-five years. Recently, IS seems to have found a renewed impetus in the framework of the Circular Economy (CE), a novel approach to sustainability and
\end{abstract}

\footnotetext{
${ }^{1}$ Please cite this work as follows: Cecchin, A., Salomone, R. Deutz, P., Raggi, A., and Cutaia, L., 2020, Relating industrial symbiosis and circular economy to the sustainable development debate. In Salomone, R., Cecchin, A., Deutz, P., Raggi, A. and Cutaia, L. (Eds) Industrial symbiosis for the circular economy: Operational experiences, best practices and obstacles to a collaborative business approach. Springer: Switzerland, pp. 1-25
} 
Sustainable Development (SD) that has been rapidly gaining momentum worldwide. This opening chapter of the book provides an introduction to the concepts of IS, CE and SD, and summarizes their complex evolutionary paths, recalling the relevant developments and implementation challenges. In addition, the authors point out the divergences and interrelations of these concepts, both among themselves and with other related concepts and research fields, such as industrial ecology, ecological modernization and the green economy. Furthermore, the potential contribution of IS and the CE to SD is briefly discussed, also highlighting critical issues and trade-offs, as well as gaps in research and application, especially relating to the social component of sustainability. Particular attention is given to the potential role of IS in the achievement of targets connected to the Sustainable Development Goals set in the UN Agenda 2030. The recent advances in the IS and CE discussion in the context of the SD research community are further explored, with particular emphasis on the contribution of the International Sustainable Development Research Society (ISDRS) and its $24^{\text {th }}$ annual conference organised in Messina, Italy, in 2018. The programme of that conference, indeed, included specific tracks on the abovementioned themes, the contents of which are briefly commented on here, after an overview on the whole conference and the main cross-cutting concepts emerged. In the last part of the chapter, a brief description of the chapters collected in the book is presented. These contributions describe and discuss theoretical frameworks, methodological approaches and/or experiences and case studies where IS and the principles of CE are applied in different geographical context and at different scales to ultimately improve the sustainability of the current production patterns.

Keywords: Industrial Symbiosis, Circular Economy, Sustainable Development, Sustainable Development Goals, Sustainability, Industrial Ecology, Green Economy, Ecological Modernisation.

\subsection{Introduction}

A growing interest in sustainability issues and in how to build a resilient and sustainable economy can be seen in the content and direction of policy agendas, academic research, and company strategies. Whilst the appropriateness and sincerity of individual initiatives can and should be debated, there is little room to doubt the prominence of the sustainability discourse from international institutions (e.g., UN, EU) albeit with variable national responses. Sustainable development (SD) can be seen as the overarching goal of these initiatives. Industrial symbiosis (IS), the main focus of this book, is a business focused approach to promoting sustainability by recovering residues from one entity for use in another (Chertow 2000). Although more than 20 years old by name (and much older in practice), over the last five or six years IS has become a sub-field of a new concept, the Circular Economy (CE). The term "circular economy" has risen to a swift and remarkable prominence to 
become one of the most widely applied and researched approaches to the implementation of SD (Korhonen et al. 2018a; Merli et al. 2018). This chapter explores the relationship between these three terms and considers the co-development of policy and academic approaches.

The UN-sponsored Brundtland Report (WCED 1987) popularised the term SD, providing the definition ${ }^{2}$ which remains the benchmark for many policy makers and scholars. Arguably, what was inspirational about this definition was that it shifted the focus of the discussion from "what should not be done to stressing what should and can be done" (Mitcham 1995:315). Earlier approaches to incorporating resource management and environmental quality into economic considerations included the deployment of economic models as rationale for the need to restrain development in response to Malthusian concerns for the effects of unrestricted growth (e.g., prominently the Club of Rome: Meadows et al. 1972; Mesarovic and Pestel 1974). These concerns coincided with pressure from less wealthy countries for a share of the benefits of economic growth. Perhaps unsurprisingly, the term that captured the imagination of policy makers and academics alike was one that stressed there was a positive route to be taken (requiring a balance between the three pillars of environment, economy and society). However, although the Brundtland report offers numerous suggestions, the term itself is an ideal goal, not a road map. Rather, SD quickly became a buzzword (Simon 1989), contributing to deaden the most revolutionary aspects embedded in the core of this novel idea. There are notoriously many academic definitions (Bolis et al., 2014). Furthermore, the term is variously used (or abused) by policy makers and companies to justify their actions (Eden 2000), although arguably a consensus is beginning to emerge (Vermeulen 2018).

Over the last thirty years the challenges of implementing SD, however understood, have become increasingly apparent. This is indicated by the changing rhetoric from the UN, where ambitions are little altered since the first Earth Summit 1992, but there is increasing awareness of the complexities (see the statements following the 2002 and 2012 Earth Summits). In addition, new terms have been coined to promote the implementation and/or the theoretical understanding of SD: Figure 1.1 provides a schematic summary of the development of such terms.

2 Development that "meets the needs of the present without compromising the ability of future generations to meet their own needs" (WCED, 1987, 8) 


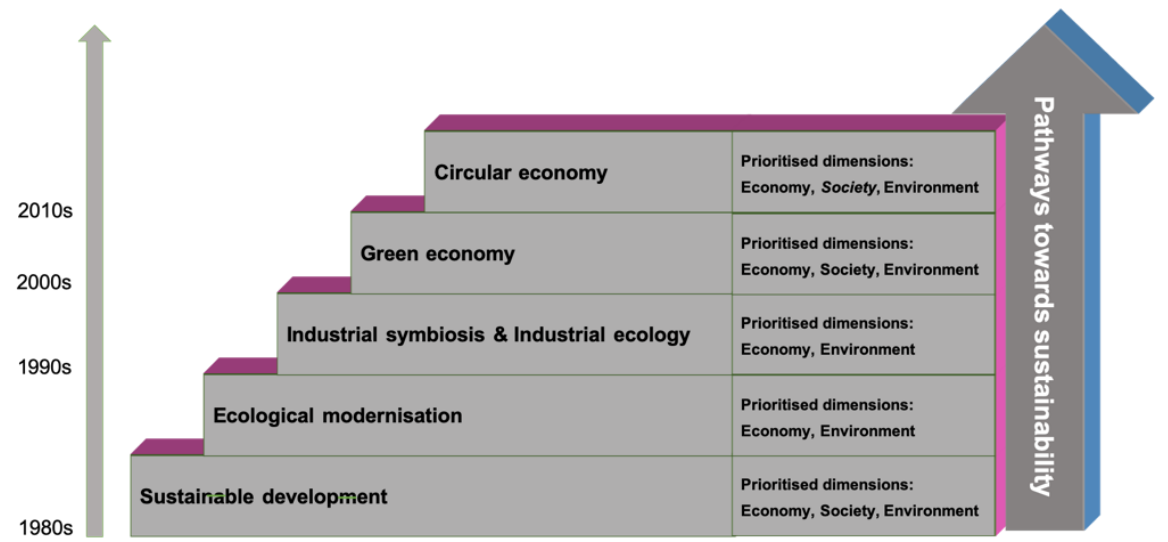

Fig. 1.1 A schematic representation of the key concept discussed in the chapter organized according to a temporal scale to indicate their origin and/or take-up in the literature. Note that all these terms continue in usage to the present day. An indication of the extent to which these concepts (as typically applied) cover the three pillars of SD is also provided in the figure. Efforts to research and apply the social aspects of the circular economy are at early stages.

The Rio Summit in 2012 promoted the idea of green growth - i.e., not just that economic development should be environmentally benign, but that the environmental agenda itself can generate growth. A further expectation of the green economy is that it should fulfil social sustainability criteria as well as economic and environmental ones.

The green economy has itself become a major area of academic research (Bailey and Caprotti 2014; Loiseau et al. 2016), building on and expanding the academic concept of Ecological Modernisation (EM). The latter term refers to the potential (to some extent observed) for innovations to bring simultaneously economic and environmental benefits (Jänicke et al. 1989; Hajer 1995; Gouldson and Murphey 1998). Thus, regulatory implementation of environmental measures opens economic opportunities as well as potentially increasing costs. Social issues are most typically not considered, or it is assumed that social and economic benefits come together. EM became a substantial area of academic debate (Mol and Sonnenfeld 2000), but although arguably EM is the hallmark of EU environmental policy, the EU itself refers to its aims as SD (Baker 2007). Both these terms fell a little out of favour, however, driven perhaps by the need of academics to say something new in a world where the issues are depressingly familiar. But SD has once again received a major boost as a subject for academic research ${ }^{3}$ as a result of an intervention by the UN. Following the mixed success of the Millennium Development Goals, the

${ }^{3}$ This is not to miss the large volume of research relating to issues that come under the heading of SD, such as environmental management, or sustainability transitions. 
debates around and announcement of the Sustainable Development Goals (SDG 2015) has put the SD firmly back on the academic agenda. The SDGs themselves are subject for debate (e.g., Spaiser et al. 2017), as well as providing a holistic framework for the myriad activities covered by the targets underlying the goals.

The $\mathrm{CE}$ concept follows a similar evolutionary path to $\mathrm{SD}$, but at a faster pace. The CE is an approach to resource efficiency using design of products, processes and infrastructure to maximise the economic benefit from resources by keeping them in circulation and avoiding residues leaking into the environment. It is not, to a large extent, a new idea. The roots of the concept can be traced to prior concepts and fields of study including not just IS (itself a sub-field of industrial ecology), but also cradle to cradle, regenerative design, cleaner production, life cycle management, ecological economics, performance economy, zero waste management (EMF 2013; Geissdoerfer et al. 2016; Reike et al. 2018; Korhonen et al. 2018b). However, the formalisation and subsequent popularisation of the $\mathrm{CE}$, has rapidly outstripped that of any of the contributory concepts.

The crucial contribution of the policy making sphere to the rise of the CE has had a significant impact on the academic world as well, which has rapidly attempted to fill the apparent knowledge gap and create some specific theoretical and operative frameworks to support the decision-makers' work. Policy activity provides an object for study for academics, who are increasingly under pressure to show not just policy relevance, but effect (Deutz and Ioppolo, 2015). Such influence of policy on academic activity becomes quickly evident by cross-checking the key milestones of the $\mathrm{CE}$ regulation with the scientific production on $\mathrm{CE}$. China introduced the concept of CE in 2002, but only in 2009 the "Circular Economy Promotion Law" took effect and was incorporated in the 11th (2006-2010) and 12th (2011-2015) five-year plans for National Economic and Social Development (McDowall et al. 2017; Murray et al. 2017). However, the Chinese use of the term CE is essentially as an equivalent to industrial ecology (Yuan et al. 2006); the explosion in academic and policy interest outside of China has followed the adoption of a more broadly defined concept by the EU. In 2015, the European Commission launched its ambitious initiative "Closing the loop: An EU Action Plan for the Circular Economy Package" (European Commission 2015), which was fully completed in 2019 by identifying and, to some extent, implementing 54 measures aimed at achieving a CE within the European Union (European Commission 2019). Lieder and Rashid (2016) conducted a literature review on CE considering the major contributory fields and geographical focus of research. They found that the number of publications in the field started growing at an almost regular pace since 2009 (also confirmed by Geissdoerfer et al. 2016), and that in the period of 2005-2015 the predominant geographical focus was China, while European research started showing a significant increase from 2015 (Geissdoerfer et al. 2016). Furthermore, the breadth of the concept has attracted not just those involved in the component fields, but other diverse social science backgrounds (e.g., Hobson 2016).

One of the strongest criticisms of the concept of SD is that it has not aimed at creating a clear alternative to the dominant development strategies. Rather it has 
provided a generic adjustment in order to include social and environmental aspects in the established models, without setting clear criteria and paths (Du Pisani 2007). CE seems to provide a better-defined alternative model to the current pattern of production and consumption, at least from a theoretical viewpoint. It proposes a radical shift from the dominant linear model (take-make-use-dispose) to a cyclical and restorative model (EMF 2013; WRAP 2019). Therefore, building a CE entails the adoption of a systemic approach in designing, planning and managing production and consumption systems, with the purpose of using resources (materials, energy, water) the longest time possible within the system itself, and minimising the need for raw materials and non-renewable resources. This is the reason why CE has the potential of becoming an effective operative strategy to pursue a SD. CE can identify and build a path to reach sustainability, a key element that the core concept of SD has never clearly outlined (Sauvé et al. 2016).

This reasoning, however, also applies to the precursor concepts of CE. Industrial ecology (IE) draws on a metaphor with ecosystems, asserting that taking lessons from nature can make economic systems more energy and material efficient ('life cycle' thinking, system scale optimisation, conceptualising material recovery as the closing of loops) (Tibbs 1991; Ayres and Ayres,1996). IS is a prominent sub-field of IE which focuses on the closing of pre-consumer (i.e., industrial) loops by capturing the residues from one entity as the inputs for another (e.g., Chertow 2000). Both can be seen as forms of EM (innovation with economic and environmental benefits), and promoting aspects of SD (Deutz 2009). But whereas the broad definition of SD implies the possibility of maintaining the present economic system (but more benign socially and environmentally), and EM suggests financial advantage (at least to some), IE and IS have a specific set of actions attached (Deutz 2009). IS, part of the family of IE activity, was taken up at first largely by engineers as offering a solution to problems of industrial waste. Other works subsequently began to consider the economic, regulatory barriers to IS. This combination of political acceptability, economic desirability and deceptively simple technological requirements led to a large body of academic research and widespread policy interest in IS, which fed off each other. The UK government's support for the National Industrial Symbiosis Programme (2005-2012), which inspired implementation efforts abroad (Wang et al. 2015) as well as research (Jensen et al. 2011; Paquin and HowardGrenville 2012).

However, the terms IE and IS never captured the policy, public or academic interest in the way that the CE already has. This may partially lie in the efforts of the Ellen MacArthur Foundation to promote the CE, backed by an extraordinary array of corporate sponsors. Although purely speculative, the terms "ecology" and "symbiosis" may be more off-putting to non-academic audiences than "economy", though hardly more difficult to understand. Potentially, the far broader nature of the term "CE" enables a preoccupation with recovery, rather than emphasis on less positive sounding waste, and also offers the tantalising prospect that with the aid of design we can avoid resource/pollution problems altogether. In addition, the ad- 
vantages of IS in terms of providing a specific route to SD proved difficult to accomplish, requiring high levels of collaboration, information exchange and a technical match between the inputs and outputs of diverse organisations (Deutz and Gibbs 2008). Building a CE likewise means introducing innovative patterns of interactions between actors based on cooperation and sharing mechanisms (Korhonen et al. 2018a). It remains to be seen whether the greater policy drive and present enthusiasm for $\mathrm{CE}$ is sufficient to overcome such challenges; potentially other $\mathrm{CE}$ options require less specific collaboration than IS. For now CE is perhaps the ultimate SD concept, incorporating optimism, potential economic gain, and such a wide variety of potential actions that for academics and other stakeholders alike there is something for almost everyone, whilst avoiding too much scrutiny on any one option.

\subsection{Bridging Circular Economy and Sustainable Development}

In line with $\mathrm{SD}, \mathrm{CE}$ aims at generating an overall system shift towards a more responsible and efficient way of managing natural and technological resources. However, although it would appear that the CE offers approaches to development that would meet the criteria of SD (at least allowing economic activity that is arguably less material and energy intensive than non-circular alternatives), the conceptual relationship between CE and SD remains unclear (Geissdoerfer et al. 2017). In the terms discussed herein, it remains a matter of debate to what extent the CE is seen as an EM concept as opposed to a green economy concept - i.e., essentially, does it incorporate social aspects of sustainability? Social benefits for the CE have been proposed, but are untested (Millar et al., 2019).

Surprisingly, or perhaps resulting from the lacking of a historical perspective, many scholars and policymakers overlook the link between CE and SD. The EMF's list of CE principles in their guide for CE implementation (2015) does not include a social principle. In their analysis of 114 definitions of $\mathrm{CE}$ in peer-reviewed and other works, Kirchherr and colleagues (2017) could establish an explicit connection between the $\mathrm{CE}$ and the notion of SD in only $12 \%$ of the definitions, while $13 \%$ mentioned all three components (environmental, social and economic) commonly associated to SD. The most common element between the 114 definitions was resource efficiency, which fits the widely perceived origins of CE in concepts which do explicitly relate to that, such IE. A question arises, though: do we really need a precise definition of CE? Blomsma and Brennan (2017) conceptualized CE as an umbrella concept, namely a broad concept that is used loosely to encompass previously unrelated concepts by focusing on their shared characteristics (Blomsma and Brennan 2017; Hirsch and Levin 1999). This approach may help protect the ideas that fed into $\mathrm{CE}$, and avoid the term becoming either deeply contested or so broad that it is simply a synonym for SD. 
However, as has been pointed out previously, the CE's area of interest is the production and consumption system, which is a relevant part of our current model of development but not the whole picture. In contrast to EM approaches, though, there are elements of degrowth in CE strategies (Schroder et al. 2019). Approaches to circularity like repair and reuse, or sharing practices, will not only keep them out of the waste stream, but would be expected to also reduce demand for new goods. The employment implications of that are uncertain, though there will likely be geographic consequences as the centres of manufacturing are offset from the loci of affluent western consumers who tend to be the target of degrowth visions. Whether their poorer neighbours are content with repaired cast offs also remains to be seen.

The "CE era" is still at its early stages, and multiple issues and trade-offs related to spatial, temporal and scale impacts of applying the CE's principles to the current production and consumption patterns have not been yet extensively explored. There are still multiple potential "unintended consequences", while implementing a CE, that need to be properly addressed (Murray et al. 2017). For instance, boosting a CE-oriented market in a given region can generate negative socioeconomic and environmental impacts in a different geographical context. Such issues can to an extent be addressed, or at least monitored, by the life cycle assessment tools. These need to be refined to be suited to the principles of the $\mathrm{CE}$, including the consideration of social aspects (Niero et al. 2016; Kalmykova et al. 2018). However, there may be limited opportunities for those measuring life cycle impacts to influence the geographic outcome of economic activity. Such wider social/geographic and development issues have been discussed with respect to industrial ecology (Deutz et al. 2015), and apply equally to the CE. A notorious example is related to some unsustainable dynamics of global supply chains, such as the flow of some types of waste from developed to developing countries, shifting the environmental burden of a product life cycle outside the main market, while eventually receiving the final benefit of the recovering process (e.g. recycled raw materials). It is worth while noting that this conflictual dynamics at global scale is still a key problem in the broader field of SD, in particular when dealing with relations between developed and developing countries. Thus, identifying CE strategies that are able to responsibly address spatial and multiscale interactions would greatly contribute to SD at the global scale as well.

\subsection{The contribution of Industrial Symbiosis to the Sustainable Development Goals}

As mentioned, IS is a strategy for recovering pre-consumer residues for use by another entity. Although the concept of IS originated and developed within the field of IE, it has from the early CE literature been recognised as essential element of the CE (Saavedra et al. 2018), which is particularly apparent in the Chinese literature (Yuan et al., 2006; Wen et al., 2018). The whole CE scholar community - in an 
explicit or implicit way - acknowledges the key role of IS in shaping and implementing the concept of CE (among others: Ghisellini et al. 2015; Lieder and Rashid 2016; Murray et al. 2017; Korhonen et al. 2018a; Merli et al. 2018; Baldassarre et al. 2019), and so too the policymakers (Su et al. 2013; WEF 2014; European Commission 2015; McDowall et al. 2017). Indeed, IS provides the definition of what can be considered the meso-level perspective of circularity ${ }^{4}$. Geographically, IS is often seen as a local to regional scale initiative, though in practice loop closing may occur at any scale up to global (Lyons, 2007).

The potential of IS in the promotion of SD can be seen fairly clearly as promoting resource efficiency (material, energy, water) for industry, which has been argued to generate cost savings, with increased competitiveness and consequent potential for social benefits (primarily envisaged as job-related) (Dunn and Steinemann, 1998). In a recent publication, Schroeder and colleagues (2019) identified a list of potential contributions of IS to the UN SDGs (United Nations 2015). More specifically, the authors found a strong association between IS and SDG 3 "Good health and wellbeing" (Target 3.9), SDG 6 "Clean water and sanitation" (Target 6.3), SDG 8 "Decent work and economic growth" (Target 8.2), SDG 9 "Industry, innovation and infrastructure" (Target 9.4), and SDG 12 "Responsible production and consumption" (Target 12.4). Based on the collection of works presented in this book, it is the authors' opinion that IS can contribute to achieving even more SDG's Targets - in particular within the SDG 9 and 12 - and further SDGs as well. Table 1 summarises the potential contributions of IS to the United Nations SDGs, and identify some case studies in the book that can provide an example of such contribution.

${ }^{4}$ Many authors (such as: Yuan et al. 2006; Geng et al. 2012; Linder et al. 2017) pointed out that there are three perspectives in the implementation of CE strategies:

- $\quad$ the macro level perspective aims to adjust the global and/or national economy structure promoting sustainable production and consumption activities through efforts in designing and implementing proper public policies;

- $\quad$ the meso level perspective refers to closing resource loops mainly developing industrial symbiosis initiatives and eco-industrial parks;

the micro level perspective focuses on products, companies and consumers.

Some authors identify a fourth level of circularity (e.g.: Saidani et al. 2017; WBCSD 2018), the nano level, proposing it as the lowest level of analysis possible referred to products and components, while at the micro level refers to companies and consumers. 
Table 1.1. IS potential contribution to the United Nations SDGs (Source: United Nations 2015, authors' elaboration). Table lists relevant SDGs and most pertinent targets; the listed chapter(s) provide examples of aspects of IS which could provide support towards meeting the target according to the editors' interpretation,

\begin{tabular}{|c|c|c|}
\hline $\begin{array}{l}\text { Sustainable Devel- } \\
\text { opment Goal }\end{array}$ & Specific Target* & $\begin{array}{l}\text { Reference in book } \\
\text { chapters** }\end{array}$ \\
\hline $\begin{array}{l}\text { SDG } 2 \\
\text { End hunger, } \\
\text { achieve food secu- } \\
\text { rity and improved } \\
\text { nutrition and pro- } \\
\text { mote sustainable } \\
\text { agriculture }\end{array}$ & $\begin{array}{l}2.4 \text { By } 2030 \text {, ensure sustainable food production } \\
\text { systems and implement resilient agricultural prac- } \\
\text { tices that increase productivity and production, that } \\
\text { help maintain ecosystems, that strengthen capacity } \\
\text { for adaptation to climate change, extreme weather, } \\
\text { drought, flooding and other disasters and that pro- } \\
\text { gressively improve land and soil quality }\end{array}$ & Chapter 12 \\
\hline $\begin{array}{l}\text { SDG } 3 \\
\text { Ensure healthy } \\
\text { lives and promote } \\
\text { well-being for all at } \\
\text { all ages }\end{array}$ & $\begin{array}{l}3.9 \text { By } 2030 \text {, substantially reduce the number of } \\
\text { deaths and illnesses from hazardous chemicals and } \\
\text { air, water and soil pollution and contamination }\end{array}$ & $\begin{array}{l}\text { All chapters (as in- } \\
\text { direct effect of re- } \\
\text { ducing waste gen- } \\
\text { eration through IS) }\end{array}$ \\
\hline $\begin{array}{l}\text { SDG } 6 \\
\text { Ensure availability } \\
\text { and sustainable } \\
\text { management of wa- } \\
\text { ter and sanitation } \\
\text { for all }\end{array}$ & $\begin{array}{l}6.4 \text { By } 2030 \text {, substantially increase water-use effi- } \\
\text { ciency across all sectors and ensure sustainable } \\
\text { withdrawals and supply of freshwater to address } \\
\text { water scarcity and substantially reduce the number } \\
\text { of people suffering from water scarcity }\end{array}$ & $\begin{array}{l}\text { Chapters 2, 3, } 7, \\
11,12\end{array}$ \\
\hline \multirow{2}{*}{$\begin{array}{l}\text { SDG } 7 \\
\text { Ensure access to } \\
\text { affordable, reliable, } \\
\text { sustainable and } \\
\text { modern energy for } \\
\text { all }\end{array}$} & $\begin{array}{l}7.2 \text { Increase substantially the share of renewable en- } \\
\text { ergy in the global energy mix by } 2030\end{array}$ & Chapters 11, 12 \\
\hline & $\begin{array}{l}\text { 7.3 By } 2030 \text {, double the global rate of improvement } \\
\text { in energy efficiency }\end{array}$ & $\begin{array}{l}\text { Chapters 2, 3, 7, 9, } \\
10\end{array}$ \\
\hline \multirow{2}{*}{$\begin{array}{l}\text { SDG } 8 \\
\text { Promote sustained, } \\
\text { inclusive and sus- } \\
\text { tainable economic } \\
\text { growth, full and } \\
\text { productive employ- } \\
\text { ment and decent } \\
\text { work for all }\end{array}$} & $\begin{array}{l}\text { 8.2 Achieve higher levels of economic productivity } \\
\text { through diversification, technological upgrading } \\
\text { and innovation, including through a focus on high- } \\
\text { value added and labour-intensive sectors }\end{array}$ & $\begin{array}{l}\text { All chapters (IS can } \\
\text { improve productiv- } \\
\text { ity by avoiding or } \\
\text { limiting waste gen- } \\
\text { eration, and intro- } \\
\text { duce innovative } \\
\text { processes and tech- } \\
\text { nologies) }\end{array}$ \\
\hline & $\begin{array}{l}\text { 8.4 Improve progressively, through } 2030 \text {, global re- } \\
\text { source efficiency in consumption and production } \\
\text { and endeavour to decouple economic growth from } \\
\text { environmental degradation, in accordance with the }\end{array}$ & $\begin{array}{l}\text { All chapters (as in- } \\
\text { direct effect of re- } \\
\text { ducing waste gen- } \\
\text { eration through IS) }\end{array}$ \\
\hline
\end{tabular}




\begin{tabular}{|c|c|c|}
\hline & $\begin{array}{l}10 \text {-year framework of programmes on sustainable } \\
\text { consumption and production, with developed coun- } \\
\text { tries taking the lead }\end{array}$ & \\
\hline \multirow{4}{*}{$\begin{array}{l}\text { SDG } 9 \\
\text { Build resilient in- } \\
\text { frastructure, pro- } \\
\text { mote inclusive and } \\
\text { sustainable indus- } \\
\text { trialization and fos- } \\
\text { ter innovation }\end{array}$} & $\begin{array}{l}9.2 \text { Promote inclusive and sustainable industrializa- } \\
\text { tion and, by 2030, significantly raise industry's } \\
\text { share of employment and gross domestic product, } \\
\text { in line with national circumstances, and double its } \\
\text { share in least developed countries }\end{array}$ & Chapters 6, 12 \\
\hline & $\begin{array}{l}9.3 \text { Increase the access of small-scale industrial and } \\
\text { other enterprises, in particular in developing coun- } \\
\text { tries, to financial services, including affordable } \\
\text { credit, and their integration into value chains and } \\
\text { markets }\end{array}$ & Chapters 6, 12 \\
\hline & $\begin{array}{l}\text { 9.4 By } 2030 \text {, upgrade infrastructure and retrofit in- } \\
\text { dustries to make them sustainable, with increased } \\
\text { resource-use efficiency and greater adoption of } \\
\text { clean and environmentally sound technologies and } \\
\text { industrial processes, with all countries taking action } \\
\text { in accordance with their respective capabilities }\end{array}$ & $\begin{array}{l}\text { All chapters (IS } \\
\text { contributes to make } \\
\text { industrial processes } \\
\text { more sustainable by } \\
\text { improving waste } \\
\text { management prac- } \\
\text { tices) }\end{array}$ \\
\hline & $\begin{array}{l}\text { 9B Support domestic technology development, re- } \\
\text { search and innovation in developing countries, in- } \\
\text { cluding by ensuring a conducive policy environ- } \\
\text { ment for, inter alia, industrial diversification and } \\
\text { value addition to commodities }\end{array}$ & Chapters 6, 7, 12 \\
\hline \multirow{4}{*}{$\begin{array}{l}\text { SDG } 12 \\
\text { Ensure sustainable } \\
\text { consumption and } \\
\text { production patterns }\end{array}$} & $\begin{array}{l}12.2 \text { By } 2030 \text {, achieve the sustainable management } \\
\text { and efficient use of natural resources }\end{array}$ & $\begin{array}{l}\text { All chapters (IS fos- } \\
\text { ter the use of waste } \\
\text { as raw material) }\end{array}$ \\
\hline & $\begin{array}{l}12.3 \text { By } 2030 \text {, halve per capita global food waste at } \\
\text { the retail and consumer levels and reduce food } \\
\text { losses along production and supply chains, includ- } \\
\text { ing post-harvest losses }\end{array}$ & Chapters $8,11,12$ \\
\hline & $\begin{array}{l}12.4 \text { By } 2020 \text {, achieve the environmentally sound } \\
\text { management of chemicals and all wastes through- } \\
\text { out their life cycle, in accordance with agreed inter- } \\
\text { national frameworks, and significantly reduce their } \\
\text { release to air, water and soil in order to minimize } \\
\text { their adverse impacts on human health and the en- } \\
\text { vironment }\end{array}$ & $\begin{array}{l}\text { All chapters (IS } \\
\text { aims at reducing } \\
\text { the generation of } \\
\text { waste and related } \\
\text { environmental im- } \\
\text { pacts) }\end{array}$ \\
\hline & $\begin{array}{l}12.5 \text { By } 2030 \text {, substantially reduce waste generation } \\
\text { through prevention, reduction, recycling and reuse }\end{array}$ & $\begin{array}{l}\text { All chapters (main } \\
\text { goal of IS) }\end{array}$ \\
\hline
\end{tabular}

* Underline added by authors. The extent of the potential contribution of IS to meet the SDG Targets can vary, from a very limited impact (e.g. Targets 7.2 and 7.3) to a more significant contribution (e.g. Targets 12.4 and 12.5).

** Selection of case studies discussed in the book that can provide an example of IS contribution to a specific SDG target 
A major aim of this text is to further the understanding of the interrelationships between SD, CE and IS in order to promote their further development. By presenting eleven research papers in the field of IS, this book aims at exploring the role of IS as a tool to implement the concept of CE and ultimately, in line with what we have mentioned above, to give a pragmatic contribution to achieve the ambitious targets globally set by the SDGs. This book tackles this by exploring a number of case studies where the principles of $\mathrm{CE}$ are put into practice, prominently including IS, in order to strengthening the role of $\mathrm{CE}$ as an effective tool to move towards a more sustainable future.

\subsection{Advancing the IS and CE discussion within the SD research community: the contribution of the International Sustainable Development Research Society (ISDRS) Conferences}

The International Sustainable Development Research Society (ISDRS) is a global network of SD professionals that links researchers in academia and implementation practice from all continents to each other (ISDRS 2019). The ISDRS organizes annual conferences structured in different theme tracks that incorporate the Sustainable Development Goals (SDGs) set in the UN Agenda 2030 (United Nations 2015). During the conferences, the delegates have the opportunity to share their researches, approaches and innovative ideas on the concept and practice of sustainability, highlighting the multiple challenges in meeting SDGs. Conferences are also an occasion to hear about a number of successful initiatives to put SD in practice, as well as the barriers, including political, technical and institutional complexities, that still limit a concrete implementation and diffusion of SD practises.

\subsubsection{An overview on the 2018 ISDRS Conference "Actions for a Sustainable World: from theory to practice" in Messina (Italy)}

The 24th ISDRS Conference has been held in Messina (Italy) in June 2018. The theme of the Conference "Actions for a Sustainable World: from theory to practice" aimed to create an open debate with major emphasis on which are the practical and effective strategies and solutions to build a sustainable world; how policy-makers, scientists and researchers are developing theoretical and methodological frameworks for SD, and decision-makers, private and public organizations, citizens are translating them into real practice.

From the wide, articulated and often exciting debate that took place during the three day-conference (in which almost 400 presentations have been made from 
scholars and practitioners coming from different countries, and reporting on very different experiences) some main cross-cutting concepts emerged from the dialogues had in the 3 plenary sessions, 3 poster sessions and 63 parallel sessions.

The first cross-cutting concept is transdisciplinarity. The emerging field of transdisciplinary research has been widely discussed in most of the tracks, with the goal of raising critical questions as the forms of knowledge co-production needed towards meeting the 2030 agenda for SD. Transdisciplinary research promises to transcend disciplinary boundaries through research collaboration between actors in academia, business, government and civil society, usually with a participatory dimension, community empowerment, and social learning. There are high expectations that such collaboration can address deep rooted sustainability challenges. However, little work has been carried out in exploring: 1) the tensions and dilemmas of transdisciplinary research with actors outside of academia: 2) the practical and ethical challenges of realizing such research 'in the field'; and 3) how to conduct effectively these empirical research processes and better understand their impact on sustainability transitions. Nevertheless, many examples of transdisciplinary methodologies have been reported during the conference, such as, for example, in projects about education for SD, energy efficiency in urban neighbourhoods, renewable energy in rural and remote communities, management of land use and water reserves, and anti-corruption initiatives (as corruption is considered one of the issues hindering progress towards SD and ultimately the global eradication of poverty).

The second cross-cutting concept that transversally entered the discussion in all of the conference tracks is the relevance of policy and governance in the transition towards a sustainable society. Public policies for SD and the diverse forms of governance that emerge from markets and civil society have been discussed, ranging from local to global scales, implemented in diverse spatial contexts, and applied in different sectors: waste management, energy management, water management, mobility, urban planning, food security, industrial development, human rights, poverty, and so on. The policy domain has been observed and discussed also from different perspectives: a) how academic research can contribute to help policy-makers to make better decisions for SD; b) how policy-makers can implement instruments which will effectively help businesses eco-innovate and start the transition to SD; c) how policy-makers can effectively communicate and spread recommendations to help the different stakeholders deal with sustainability challenges. Even if sustainability is a cornerstone of modern policy making and is prominent in the agenda of many organizations and governments globally, the various discussions all reiterated that pursuing SDGs depends on the existence of strong, well-equipped public network of institutions at local, national and international levels. Creating a more effective and coherent global governance will be a futile exercise if it is not reflected in effective local and national counterparts, strengthening existing institutions and creating new bodies in areas where governance gaps exist. Another issue that has been pointed out is that policy tools and instruments able to simultaneously understand, analyses and face social, environmental and economic sustainability challenges, with a holistic view, are still limited. 
The third cross-cutting concept is multi-dimensionality. The multidimensional character of SD is a well-known concept, referring to its economic, social, and environmental components and the ability to balance them for the benefit of present and future generations. Of course, this is a relevant and accepted issue also in the UN Agenda 2030 and all conference participants emphasized it by stressing the importance of addressing the different dimensions of sustainability and including them in their researches with a system and holistic approach. It was noted however that, during the conference, there has been little discussion on practices including the 3 pillars of sustainability in an integrated perspective. Indeed, a huge number of presentations reporting on practical experiences were about the environmental pillar of sustainability, in some cases including also the economic dimension, whereas social issues, even if object of several presentations, have only been peripherally and sporadically analysed with a fully integrated sustainability multidimensional perspective. Indeed, the concept of social sustainability is more difficult to analyse, comprehend, define, and incorporate into sustainability projects and planning than the other dimensions of sustainability. The main challenges and obstacles are represented by some of its peculiar characteristics that need special attention and dedicated tools and methods to be efficiently taken in consideration. These aspects could be grouped into two main types of problems: a) social goals are extremely ambitious to be achieved, because social welfare, quality of life, social justice, cultural diversity, gender equity, workers' rights, and so forth, involve finding solutions to very complex problems worldwide, such as hunger, malnutrition, armed conflicts, corruption, natural disasters, human trafficking, terrorism, intolerance, diseases, and so on; b) there is no standardized and scientifically accepted method for measuring social sustainability, as well as it is still unclear how to manage tradeoffs between environmental, economic and social goals, that often may occur into sustainability research and practises.

The fourth cross-cutting element refers to measuring sustainability. In almost all the conference tracks emerged that there is a growing need to measure the impact of policy and governance initiatives and projects in order to monitor the achievement of sustainability targets. Different methods and frameworks have been discussed in detail, with growing consensus that metrics should be able to address the different issues impacting SD challenges in a system and life cycle perspective. It is interesting to note that about $10 \%$ of the contributions presented at the conference propose life cycle thinking assessment methods to monitor and assess one of more dimensions of sustainability.

Among the different theme tracks of the conference, two are the ones mainly related with the key concepts of this book: "Circular economy, zero waste \& innovation" and "Industrial symbiosis, networking and cooperation as part of industrial ecology". A summary of the dialogues had during the conference within these tracks is presented in the two following sub-sections. Large part of the manuscripts collected in this book are a selection of the contributions presented in these two tracks. 


\subsubsection{The theme track "Circular economy, zero waste \& innovation"}

The Circular Economy and Zero Waste track at Messina covered a wide range of topics, reflecting both the predecessor concepts and current formulations of the $\mathrm{CE}$ concept. Contributions varied from an individual company reporting on its own activity to social science studies of sustainability implications of the CE. Topics such as IS, waste reduction and waste diversion remain popular, with studies at different geographic scales and focusing on different industrial sectors. Papers explicitly tackling CE issues came from the perspective of both SME and multinational companies attempting to improve their environmental performance Within the range of approaches to loop closing discussed, several papers discussed IS. Some considered taking regional bio-economy approaches, e.g., utilising agricultural residues. Material-focused approaches concerned responses to the recovery of new materials driven by technical research. However, a number of contributions concerned the social implications of a CE, including workers' rights and institutional barriers to building a CE. The most popular theme was LCA, reflecting the Italian LCA Network conference which preceded ISDRS. Papers included both developments to LCA as a method and applications of LCA to specific case studies. Methodological discussions included implications of system boundaries (e.g., to consider future impacts), and multi-criteria decision making tools. Applications of LCA included prominently ceramic tile design and production, reflecting the economy of the host country. These papers indicate the role of collaboration e.g., between industry and research, in bringing about sustainable product innovations. Significantly, more traditional approaches to LCA were combined with methods such as surveys and interviews to gain insight into behaviour and attitudes.

\subsubsection{The theme track "Industrial symbiosis, networking and cooperation as part of industrial ecology"}

The special track on Industrial Symbiosis, networking and cooperation as part of industrial ecology at Messina gathered various contributions around the theme of IS based on different approaches: from engineering studies on pilot technologies for enhancing by-products, going through analyses of multiple case studies of existing or potential symbiotic networks (in various territorial contexts), up to social studies on the role of policies and business strategies in industrial transitions towards sustainability.

The spatial scope of the studies was rather diverse, even though mainly focused on local areas - e.g., networks of agents co-located in a municipality (e.g., Sotenäs, Sweden), industrial districts located in metropolitan areas (e.g., Bologna, Italy; Malmö, Sweden) - thus reflecting the significance of the co-localization issue in industrial symbiosis. Wider scopes included regional productive systems (Umbria, 
Italy), up to whole sectors of an economy, such as the European Union's energyintensive industries. One study involved a broad international partnership, with the aim of creating a unique network of partners with complementary expertise and competences.

The industrial sectors considered were also wide-ranging: steel industry, agrifood industry, production of innovative energy biomasses, with some studies considering numerous firms operating in various industries, thus confirming the mostly inter-sectoral nature of IS.

The subject uniting the various contributions was, obviously, IS - in some cases extended to urban symbiosis - associated with other closely related key concepts, such as the CE, energy and resource efficiency. Among the topics discussed was the need for a transition to decarbonisation. One of the studies stressed the importance of IS as a driver of decarbonisation in energy-intensive sectors, such as the steel industry. A popular topic found in various studies, according to a bio-economy approach, was bioenergy: specifically, the use of residues and by-products (such as nutrients from wastewater or $\mathrm{CO}_{2}$ from biogas upgrading) as inputs for the growing of algae to be used as energy biomass. The collective capacity of relevant actors (firms, government bodies, knowledge institutions, and others) to engage in collaborative action was stressed as a relevant factor in generating symbiotic opportunities, and the interventions enhancing it were investigated. An aspect common to almost all studies was the role of innovation, both technological and organizational, as well as new business models, in facilitating the transition towards more sustainable systems through integrated and collaborative approaches.

As regards the methodological discussion, a diversified range of methods were used: from socio-economic analyses based on interviews with relevant stakeholders to Life Cycle Assessment to quantify potential environmental impacts of symbiotic systems or specific technological solutions.

Starting from an evolution analysis approach and forecasting future developments, the contributions have highlighted the environmental and socio-economic benefits created by symbiotic networks, as well as the drivers facilitating the development of such networks. As regards the latter, one study discussed the creation of an excellence network dedicated to provide services and tools to external customers for the implementation of innovative, sustainable business and cooperation models, focusing on IS.

\section{5 "Industrial symbiosis for the circular economy": A book overview}

CE and innovative collaborative approaches such IS have been incorporated at a variety of policy levels from local to international, and in a variety of forms from top-down government mandates to bottom-up independent programs and projects. Relatively little attention, however, has been paid to examining the environmental, 
social, and economic impact of these practices, and how those impacts may be context and/or scale dependent. Given that $\mathrm{CE}$ is quickly gaining momentum worldwide, sharing knowledge and experience on CE and IS practices can bring to light and disseminate successful initiatives, as well as providing important lessons regarding obstacles and barriers for an IS implementation. This book collects and presents eleven research contributions about experiences and best practices of IS, as well as successful and unsuccessful cases (implemented or under implementation) from all over the world. By analysing and discussing a number of contributions from different contexts, this publication aims at identifying key elements, critical factors and viable approaches to utilize IS as an operational and systematic tool for transitioning towards a CE. Although all the chapters draw on IS/CE case studies or experiences with a geographical locus, some authors lay more emphasis in presenting and discussing theoretical frameworks and methodological approaches (i.e. Ormazabal et al., Cutaia et al., Simboli et al., Kulczycka et al., Debnath, van Hoof and Duque-Hernández), while others contribute to the current debate on IS and CE by providing a critical analysis of case studies (i.e. Mencherini et al., Cappellaro et al., Giordano et al., Romani et al., Cervantes et al., Shi et al.).

It is well-known that SMEs are the backbone of several national economies, even in the most industrialized countries. To facilitate SMEs in the transition to a CE, Marta Ormazabal, Vanessa Prieto-Sandoval, Javier Santos and Carmen Jaca (chapter 2) propose a supporting methodology allowing firms to appreciate the role of the $\mathrm{CE}$ in creating value and competitive advantage. The framework of that approach includes some fields of action along the life cycle of products and materials (take, make, distribute, use and recover), as well as IS, as a crosswise field. Within that framework, the methodological pathway consists of various steps: preliminary diagnosis of a company's current situation as regards its value proposition, its stakeholders, and its level of CE application, analysis of the barriers and opportunities related to the transition from a linear model to a circular one, and proposal of an action plan. To test its validity, the developed methodology was implemented as a case study in a small manufacturing company. An interesting result is that a company, despite having excellent social relationships with other co-located ones, may just have never considered sharing any business with them. It also emerged that the transition path towards a $\mathrm{CE}$ can be undertaken easily even by companies, such as SMEs, which have poor technological skills and financial resources. Furthermore, the proposed approach proved suitable to be integrated with methods, such as the Life Cycle Assessment, able to support a quantitative evaluation of the identified circular strategies.

In chapter 3, an operational tool to identify potential IS between companies is described. Laura Cutaia, Tiziana Beltrani, Valentina Fantin, Erika Mancuso, Silvia Sbaffoni and Marco La Monica present a methodology developed by ENEA - the Italian National Agency for New Technologies, Energy and Sustainable Economic Development - to audit a company's resources. This method allows to analyse in details resources in input and output (materials, energy, expertise, services, etc.), 
production processes and the local context where a company is located. By assessing such data, it is possible to recommend strategies and solutions to increase the efficiency and optimise the production processes within the company boundaries, as well as to create new opportunities for cooperation with other stakeholders at local level (IS). With regard to the latter, the authors point out that the main obstacle to establish symbiotic exchanges between companies is often related to regulatory barriers, at least in the Italian context, which do not allow waste sharing mechanisms due to a problematic classification of wastes as by-products. Therefore, even when an IS is technically feasible, economically viable and the companies involved are willing to cooperate, the regulatory context might make it unachievable. That is why the authors advocate for a change in the regulatory framework that can make IS a practical option for companies who want to improve their environmental and economic performance.

Alberto Simboli, Raffaella Taddeo, Andrea Raggi and Anna Morgante (chapter 4) present the results of a study aimed at exploring how different morphologies of industrial networks can potentially influence the development of local IS. The authors consider six industrial clusters: urban industrial areas, chemical poles, local supply networks, industrial districts, ecologically equipped industrial areas (a similar, but distinct, concept of eco-industrial park which was introduced in Italy by a national law), and innovation clusters. Drawing on their research experience in studying and developing IS in the Italian context, Simboli and colleagues discuss a number of network features related to the network nodes (i.e. number and size of companies, spatial aspects of the network, and type of industrial sector involved) and ties (i.e. types of stakeholders involved and formal/informal relationships between them, presence of network management bodies, and the relations between industrial and urban systems). The authors point out a link between the origin, evolution and spatial characterization of the industrial cluster, and the potential for establishing IS. In addition, the study confirms that the spatial and temporal dynamics of IS are context-dependent processes, but the development of a taxonomy of the industrial networks might help researchers and practitioners further explore IS at local scale.

In chapter 5, Joanna Kulczycka, Ryszard Uberman, and Ewa Dziobek present a proposal for the prioritisation of the management of the different types of mining waste and by-products generated in the production process based on the MoSCoW method. The MoSCoW method is one of the prioritization techniques used in management and business analysis to create a list of prioritised requirements. In particular, the impact of different options of waste or by-product management could first be prioritised including predicted or planned changes, in the implementation of the $\mathrm{CE}$ and of the concept of IS, in individual countries and EU policy. The analysis takes economic, financial and environmental conditions into consideration and a case study is presented showing how IS can minimise waste flow in the raw materials sector based on the Polish case of brown coal (lignite) mining. The case study pointed out that nearly all types of waste from mining and processing as well from burning coal could be successfully managed, but it needs long term vision (contracts) and investment taking into account the whole life time of the mine and close 
cooperation between mine, power plant, local administrations and SMEs. The use of tools such as Cost Benefit Analysis (CBA) and Life Cycle Assessment (LCA) could be a base for creating inputs and indicator for environmental management, and the MoScoW method seems to be a helpful tool for prioritising different options and taking a final decision.

Biswajit Debnath examines a very topical issue in waste management: the sustainability of the e-waste supply chain (chapter 6). The author draws attention to the e-waste management in developing countries, more specifically Asia and Africa, where the large part of e-waste generated worldwide ends up and it often gets managed by the informal sector. This kind of waste, if not properly treated, can create a number of environmental and health problems (due to the release of hazardous substances contained in the e-waste and to some unsustainable methods used to treat them, such as open air burning). On the other hand, the high content of valuable materials in the e-items makes the e-waste management a potentially profitable activity, in addition to provide a contribution to recovering and recirculating resources under a CE perspective. In the chapter, Debnath describes the life cycle of an e-item and critically discusses the global supply chain of the e-waste. Based on this assessment, the author outlines an IS framework for the e-waste sector, in order to optimise the resource recovery and minimize the environmental impacts of waste management. Debnath also considers the spatial component of such IS, evaluating a couple of scenarios where the symbiotic network is characterized by different levels of geographical proximity.

In chapter 7, Bart van Hoof and Juanita Duque-Hernández present a supply chain model, called Sustainable Enterprise Network methodology (RedES), which entails a collaboration among a critical mass of companies (335 private companies), universities and environmental authorities, for the dissemination of CE strategies (such as cleaner production and IS) in an emerging market context characterized by environmental and social vulnerability and limited institutional capacity (in Colombia's central region). The main objective of RedES is to promote productive transformation of firms and value chains through the application of change strategies in supply chains led by anchor organizations. Compared to other supply chain mechanisms for cleaner production and IS dissemination (e.g. technical assistance to capacity-building, sector guidelines, subsidies, etc.), the RedES experience showed larger scale and transformation potential: an increasing critical mass of firms take up cleaner production and IS practices for improvement of environmental performance, and create capacity for the triple helix through collaboration among private companies, public environmental authorities and universities. New universities and education centres will be trained and certified in order to expand the model on a national basis and contribute to the productive transformation of firms and value chains towards sustainability and green growth.

In chapter 8, Ugo Mencherini, Sara Picone, Lorenzo Calabri, Manuela Ratta, Tullia Gallina Toschi and Vladimiro Cardenia focus their contribution on the implementation of IS in the Emilia-Romagna (ER) region, one of the most advanced Italian regions as regards the implementation of a $\mathrm{CE}$. Indeed, a regional law on the 
CE was issued in 2015 in ER with the aim of increasing public awareness of those issues and enabling the transition to a more circular model. The authors, besides framing the policy context, describe some initiatives carried out in recent years in ER. Among these, the "Green - Industrial Symbiosis" project, which involved local agri-food companies and research laboratories to spread the culture of IS locally. At the end of the project, several potential synergies between companies had been identified and some of these had been studied in depth from the point of view of their techno-economic feasibility. This experience provided the basis for an ongoing international collaboration project, named TRIS ("Transition Regions Towards Industrial Symbiosis"), which involves a few European regions, including ER. This project is aimed at encouraging the sharing of good practices and developing new IS initiatives at regional level, also through dedicated policy tools. This resulted, for example, in the inclusion of IS among the strategic objectives considered by ER when funding collaborative research and innovation projects. Finally, the Food Crossing District project has focused on regional food and agricultural supply chains to enhance their by-products by developing innovative products. The main lessons learned from the experiences conducted in ER are finally identified and summarised by the authors.

Francesca Cappellaro, Laura Cutaia, Giovanni Margareci, Simona Scalbi, Paola Sposato, Maria-Anna Segreto and Edi Valpreda discuss a case study related to the Roveri Industrial District, an industrial cluster located in Northern Italy (chapter 9). The authors describe the early stages of a transition process from a traditional industrial cluster to a Smart Sustainable District. The case study provides an interesting perspective on how a collaborative approach between research institutions, government agencies and private companies can enable a shift in the management of a complex industrial cluster towards sustainability. The Roveri Industrial District, once apart from the metropolitan area of Bologna, over the years became part of the city's metropolitan system, posing new challenges (but also creating new opportunities) for the local decision-makers. Among the multiple initiatives of community engagement activated within the industrial cluster, a pilot project with a small group of companies attempted to identify potential symbiotic exchanges in the area. The results of such project highlighted the interest of some companies in exploring new ways of sharing infrastructures and services (e.g. mobility and workplace canteens), co-managing some type of waste (e.g. garden waste) and creating a "district resource manager", namely a new actor able to generate new opportunities for joint purchasing of goods and services.

Roberto Giordano, Elena Montacchini and Silvia Tedesco (chapter 10) present the results of four studies, where agricultural and food by-products were used in manufacturing new construction products. Their research, which was carried out in partnership with small and medium enterprises, explores the potential of employing rice husk in concrete manufacturing, almond shells as a thermal insulating plaster, bovine horns to manufacture mosaic tiles, and rice straw and corn cob in a new concrete product. The overall assessment of the studies shows both benefits and limitations of introducing new bio-based material in the construction sector. With 
regard to the formers, these new materials contribute to: 1) upcycling waste and byproducts (which are often a burden for the companies) to valuable products, 2) improving the rural economy by diversifying the market, 3 ) creating building products with better environmental performances (with some exceptions), and 4) moving towards a CE. On the other hand, the study identifies some issues that need to be addressed in order to develop more competitive construction products using agriculture and food by-products. Entrepreneurs need to establish new supply chains, adjust their production technologies to manufacture new products, and manage the seasonality of some agricultural by-products. Additionally, the authors stress a lack of incentives to reuse wastes and by-products, to move from R\&D phase to the commercialization scale, and to enter the market with new products with initially higher production costs. Finally, some bio-based products might not have a significantly better environmental performance than the traditional ones, negatively affecting the marketing of such new bio-materials.

A model for using IS to promote regional development drawing on local resources is presented in chapter 11 by Annalisa Romani, Margherita Campo, Giovanni Lagioia, Manuela Ciani Scarnicci and Annarita Paiano. The authors outline an approach to formulating a zero waste agribusiness model, which is based on using small to medium sized biorefineries to convert agri-industrial residues into active biomolecules for a range of applications. This is a territorial approach to IS, i.e., addressing locally produced residue streams (themselves reflecting the agricultural capabilities of the area), and applying a technological conversion in order to extract high value components that can themselves be applied within the region. Analogous to an oil refinery, a biorefinery breaks down organic matter into its constituent parts in order that each can be put to its more economically advantageous use. This contrast, for example, with bulk composting or anaerobic digestion of organics residues. Both approaches do produce products (including energy in the case of anaerobic digestion), with some economic value. But using a bulk approach misses the opportunity to recover high value elements, which, for example, may have pharmaceutical applications. The chapter outlines the refining process, using three different crops to provide examples of residue flows and potential outputs, as well as indicating potential for synergies between the three agri-industrial systems (olives, grapes and sweet chestnuts). Challenges identified include the need to match supply of residues with demand for the refined products, and issues relating to the legal classification of wastes and by-products.

In the last chapter, Gemma Cervantes, Luis Torres and Mariana Ortega introduce and assess multiple case studies of IS applied to agro-systems in Mexico. The authors present two biorefinery proposals where subtropical fruits are used as feedstock, in addition to describing some symbiotic agrifood systems in rural central Mexico. While discussing the feasibility of a biorefinery system in a rural context, Cervantes and colleagues identify a few key elements that can contribute to the success of the project: 1) a direct engagement of farmers in the early stages of the project; 2) a sound governance processes while designing and implementing a biorefinery; 3) a partnership between scientists and farmers for a responsible innovation 
in agricultural practices; and 4) a clear cost-benefit assessment for farmers. With regard to the symbiotic agri-systems, the authors further stress how social aspects play a central role while implementing a symbiotic network. The researchers point out a common bias of farmers that often does not allow them to consider a waste as an economical valuable resource. Despite the fact that most agricultural wastes can be easily employed in other processes, starting a symbiotic system is often the most critical phase. However, once a first simple IS network is established, the authors observed that farmers and entrepreneurs begin to look at it as a system and not only a cluster of separated activities. Finally, Cervantes and colleagues underline how a good balance between competition and cooperation between actors and the ability of the system to evolve and adapt are vital to ensure the symbiotic network survival.

\subsection{Conclusions}

A brief introduction on the origin and evolution of the CE and IS has been presented in this chapter, highlighting the close relationship between them and with contiguous fields of research such as industrial ecology, ecological modernization and green economy. Particular emphasis was given to contextualize the two concepts in the light of the current debate on SD, pointing out the potential contributions of IS and CE to the path towards a more sustainable society. The collection of papers gathered in this book provides the readers with a number of practices, and operative and methodological frameworks where the IS is employed to improve the overall sustainability of the current production and consumption patterns. The case studies and experiences presented and discussed in the following chapters show the potential for IS to play a role in achieving multiple Sustainable Development Goals and Targets proposed by the United Nations (2015).

\section{References}

Ayres RU, Ayres LW (1996) Industrial Ecology: Towards Closing the Materials Cycle. Edward Elgar Publishing, Cheltenham, UK

Bailey I, Caprotti F (2014) The green economy: functional domains and theoretical directions of enquiry. Environ Plann A 46(8):1797-813

Baker S (2007) Sustainable development as symbolic commitment: declaratory politics and the seductive appeal of ecological modernisation in the European Union. Environ Polit 16:297317

Baldassarre B, Schepers M, Bocken N, Cuppen E, Korevaar G, Calabretta G (2019) Industrial Symbiosis: towards a design process for eco-industrial clusters by integrating Circular Economy and Industrial Ecology perspectives. J Clean Prod 216:446-460

Blomsma F, Brennan G (2017) The Emergence of Circular Economy: A New Framing Around Prolonging Resource Productivity. J Ind Ecol 21:603-614 
Bolis I, Morioka SN and Sznelwar LI (2014) When sustainable development risks losing its meaning. Delimiting the concept with a comprehensive literature review and a conceptual model. Journal of Cleaner Production 83:7-20

Chertow MR (2000) Industrial symbiosis: literature and taxonomy. Annu Rev Energ Env 25(1):313-37

Deutz P 2009 Producer responsibility in a sustainable development context: ecological modernisation or industrial ecology? Geogr J 175:274-285

Deutz P, Gibbs D 2008 Industrial ecology and regional development: eco-industrial development as cluster policy. Reg Stud 42:1313-28

Deutz P, Lyons DI, Bi J (Eds) (2015) International Perspectives on Industrial Ecology. Edward Elgar, Cheltenham, UK and Northampton, MA, USA

Deutz P, Ioppolo G (2015) From Theory to Practice: Enhancing the Potential Policy Impact of Industrial Ecology, Sustainability 7:2259-2273

Du Pisani JA (2006) Sustainable development - historical roots of the concept. Environm Sci 3:8396

Dunn BC, Steinemann A (1998) Industrial ecology for sustainable communities. J Environ Plann Man 41(6):661-72

Eden S 2000 Environmental issues: sustainable progress? Prog Hum Geog 24:111-118

EMF (2013) Towards the circular economy. Economic and business rationale for an accelerated transition. Ellen MacArthur Foundation. https://www.ellenmacarthurfoundation.org/assets/downloads/publications/Ellen-MacArthur-Foundation-Towards-the-Circular-Economyvol.1.pdf Accessed 26 June 2019

EMF (2015) Delivering the circular economy: A toolkit for policymakers. Available online https://www.ellenmacarthurfoundation.org/news/the-ellen-macarthur-foundation-launchesdelivering-the-circular-economy-a-toolkit-for-policymakers Accessed 22082019

European Commission (2015) Communication from the Commission to the European Parliament, the Council, the European Economic and Social Committee and the Committee on an EU action plan for the circular economy. https://eur-lex.europa.eu/legal-content/EN/TXT/?uri=CELEX:52015DC0614. Accessed 26 June 2019

European Commission (2019) Report from the Commission to the European Parliament, the Council, the European Economic and Social Committee and the Committee of the Regions on the implementation of the Circular Economy Action Plan. http://ec.europa.eu/environment/circular-economy/pdf/report_implementation_circular_economy_action_plan.pdf Accessed 26 June 2019

Geng Y, Fu J, Sarkis J, Xue B (2012) Towards a national circular economy indicator system in China: an evaluation and critical analysis. J Clean Prod 23(1):216-224

Geissdoerfer M, Savaget P, Bocken NMP, Hultink EJ (2017) The Circular Economy a new sustainability paradigm? J Clean Prod 143:757-768

Ghisellini P, Cialani C, Ulgiati S (2016) A review on circular economy: The expected transition to a balanced interplay of environmental and economic systems. J Clean Prod 114:11-32

Gouldson A, Murphy J (1998) Regulatory realities - The implementation and impact of industrial environmental regulation. Earthscan, London

Hajer MA (1995) The politics of environmental discourse: ecological modernization and the policy process. Oxford University Press, Oxford

Hirsch PM, Levin DZ (1999) Umbrella advocates versus validity police: a life-cycle model. Organ Sci 10:199-212

Hobson K (2016) Closing the loop or squaring the circle? Locating generative spaces for the circular economy. Prog Hum Geog 40(1):88-104

ISDRS (2019) The International Sustainable Development Research Society home page. Available online http://isdrs.org Accessed 23 August 2019

Jänicke M, Mönch H, Ranneburg T Simnois U (1989) Economic structure and environmental impacts: east west comparisons. The Environmentalist 9:171-83 
Jensen PD, Basson L, Hellawell EE, Bailey MR, Leach M (2011) Quantifying 'geographic proximity': experiences from the United Kingdom's national industrial symbiosis programme. Resour Conserv Recy 55(7):703-712

Kalmykova Y, Sadagopan M, Rosado L (2018). Circular economy-From review of theories and practices to development of implementation tools. Resour Conserv Recy 135:190-201

Kirchherr J, Reike D, Hekkert M (2017) Conceptualizing the circular economy: An analysis of 114 definitions. Resour Conserv Recycl 127:221-232

Korhonen J, Nuur C, Feldmann A, Birkie SE (2018a) Circular economy as an essentially contested concept. J Clean Prod 175:544-552

Korhonen J, Honkasalo A, Seppälä J (2018b) Circular Economy: The Concept and its Limitations. Ecol Econ 143:37-46

Lieder M, Rashid A (2016) Towards circular economy implementation: a comprehensive review in context of manufacturing industry. J Clean Prod 115:36-51

Linder M, Sarasini S, van Loon P (2017). A metric for quantifying product-level circularity. J Ind Ecol 21(3):545-558

Loiseau E, Saikku L, Antikainen R, Droste N, Hansjürgens B, Pitkänen K, Leskinen P, Kuikman P, Thomsen M (2016) Green economy and related concepts: An overview. J Clean Prod 139:361-371

Lyons DI (2007) Loop closing, material cycling and government policy. Progress in Industrial Ecology 4:233-246

McDowall W, Geng Y, Huang B, et al. (2017) Circular Economy Policies in China and Europe. J Ind Ecol 21:651-661

Meadows DH, Meadows DH, Randers J, Behrens III WW (1972) The limits to growth: a report to the Club of Rome. Potomac Associates, Washington DC

Merli R, Preziosi M, Acampora A (2018) How do scholars approach the circular economy? A systematic literature review. J Clean Prod 178:703-722

Mesarovic M, Pestel E. (1974) Mankind at the turning point: The second report to the Club of Rome. Duttun, New York

Millar, N, McLaughlin,E, Börger, T (2019) The Circular Economy: Swings and Roundabouts? Ecological Economics 158:11-19

Mitcham C (1995) The Concept of Sustainable Development: its Origins and Ambivalence. Technol Soc 17:311-326

Mol APJ, Sonnenfeld DA (2000) Ecological modernisation around the world: an introduction. Environ Polit 9:1-14

Murray A, Skene K, Haynes K (2017) The Circular Economy: An Interdisciplinary Exploration of the Concept and Application in a Global Context. J Bus Ethics 140:369-380

Niero M, Hauschild MZ, Olsen SI (2016) Limitations and opportunities of combining Cradle to Grave and Cradle to Cradle approaches to support the circular economy. In $10^{\text {th }}$ Convegno Rete Italiana LCA 2016, 439-446

Paquin RL, Howard-Grenville J (2012) The evolution of facilitated industrial symbiosis. J Ind Ecol 16(1):83-93

Reike D., Vermeulen W. J. V. and Witjes S. (2018) The Circular Economy: New or Refurbished as CE 3.0? - Exploring Controversies in the Conceptualization of the Circular Economy through a Focus on History and Resource Value Retention Options. Resources, Conservation and Recycling. Elsevier, 135:246-264

Saavedra YMB, Iritani DR, Pavan ALR, Ometto AR (2018) Theoretical contribution of industrial ecology to circular economy. J Clean Prod 170:1514-1522

Saidani M, Yannou B, Leroy Y, Cluzel F (2017) How to assess product performance in the circular economy? Proposed requirements for the design of a circularity measurement framework. Recycling 2(1):6

Sauvé S, Bernard S, Sloan P (2016) Environmental sciences, sustainable development and circular economy: Alternative concepts for trans-disciplinary research. Environ Dev 17:48-56 
Schroeder P, Anggraeni K, Weber U (2019a) The Relevance of Circular Economy Practices to the Sustainable Development Goals. J Ind Ecol 23:77-95

Schröder P, Bengtsson M, Cohen M, Dewick P, Hoffstetter J, Sarkis J. (2019b) Degrowth withinAligning circular economy and strong sustainability narratives. Resour Conserv Recycl 146:190-191

Simon D (1989). Sustainable Development: Theoretical Construct or Attainable Goal? Environ Conserv 16(1):41-48

Spaiser V, Ranganathan S, Swain RB, Sumpter DJ (2017) The sustainable development oxymoron: quantifying and modelling the incompatibility of sustainable development goals. Int J Sust Dev World 24(6):457-70

Su B, Heshmati A, Geng Y, Yu X (2013) A review of the circular economy in China: Moving from rhetoric to implementation. J Clean Prod 42:215-227

Tibbs, HBC (1991) Industrial Ecology - An Environmental Management Agenda for Industry, Arthur D Little Inc, Boston

United Nations (2015) Transforming our world: the 2030 Agenda for Sustainable Development. https://www.un.org/ga/search/view_doc.asp?symbol=A/RES/70/1\&La Accessed 26 June 2019

Vermeulen W. J. V. (2018) Substantiating the rough consensus on concept of sustainable development as point of departure for indicator development, in Bell S. and Morse S. (eds) Routledge Handbook of Sustainability Indicators. Routledge, 59-90

Wang Q, Deutz P, Gibbs D (2015) UK-China collaboration for industrial symbiosis: a multi-level approach to policy transfer analysis. In: Deutz P, Lyons DI, Bi J (Eds) International Perspectives on Industrial Ecology. Edward Elgar, Cheltenham, UK and Northampton, MA, USA

WCED (1987) Report of the World Commission on Environment and Development: Our Common Future. World Commission on Environment and Development. https://sustainabledevelopment.un.org/content/documents/5987our-common-future.pdf Accessed 26 June 2019

WEF (2014) Towards the Circular Economy: Accelerating the scale-up across global supply chains. World Economic Forum. http://www3.weforum.org/docs/WEF_ENV TowardsCircularEconomy_Report_2014.pdf. Accessed 26 June 2019

WBCSD (2018) Circular Metrics Landscape Analysis. World Business Council for Sustainable Development. https://www.wbcsd.org/Programs/Circular-Economy/Factor-10/Metrics-Measurement/Resources/Landscape-analysis. Accessed 26 June 2019

WRAP (2019) WRAP and the circular economy: webbsite http://www.wrap.org.uk/aboutus/about/wrap-and-circular-economy Accessed August 222019

Yuan Z, Bi J, Moriguichi Y (2006) The circular economy: a new development strategy in China. J Ind Ecol 10(1-2):4-8 